\title{
Reactive power sharing among distributed generators in a microgrid by using virtual current
}

\author{
Eder A. Molina-Viloria ${ }^{1}$, John E. Candelo-Becerra ${ }^{2}$, Fredy E. Hoyos Velasco ${ }^{3}$ \\ ${ }^{1}$ Tecnologico de Antioquia, Institución Universitaria, Facultad de Ingeniería, Medellín, Colombia \\ ${ }^{2}$ Universidad Nacional de Colombia - Sede Medellín - Facultad de Minas - Departamento de Energía Eléctrica y \\ Automática, Medellín, Colombia \\ ${ }^{3}$ Universidad Nacional de Colombia - Sede Medellín - Facultad de Ciencias - Escuela de Física, Medellín, Colombia
}

\begin{abstract}
Article Info
Article history:

Received Feb 7, 2020

Revised Jan 19, 2021

Accepted Feb 5, 2021

Keywords:

Distributed generation

Microgrid

Reactive power sharing

Virtual current

Virtual impedance

ABSTRACT

This paper presents a new autonomous effective power distribution control strategy for three-phase parallel inverters. The proposal uses a controller that can provide the system with accurate power sharing among distributed generators installed in the microgrid once some load variations are presented in the network. The methodology uses a virtual current loop introduced into the current controller of the inverter to optimize the output signal, which goes directly to the PWM. This virtual current is obtained by using a virtual impedance loop. Furthermore, a small-signal model of the system is used to check stability of the proposed control strategy, which was developed for island mode operation of the microgrid. Simulations were performed for a microgrid with two generators and a load with five households and implemented in MATLAB/Simulink software. The results show that the model provides a wide margin of stability and a rapid response when electrical loads change, thus fulfilling the reactive power sharing among generators. The proposed method shows a large margin of stability and a rapid transient response of the system.
\end{abstract}

This is an open access article under the CC BY-SA license.

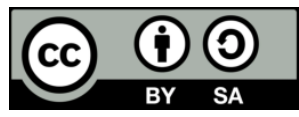

\section{Corresponding Author:}

Fredy E. Hoyos Velasco

Universidad Nacional de Colombia, Sede Medellín

Facultad de Ciencias, Escuela de Física

Carrera 65 No. 59A - 110, Medellín, 050034, Colombia

Email: fehoyosve@unal.edu.co

\section{INTRODUCTION}

In recent years, there has been a trend toward the decentralization of electricity generation; hence, the penetration of distributed generation (DG) has significantly increased and microgrids (MGs) are becoming an important concept to integrate these generation units [1]. Thus, the MG concept has been introduced as a very effective technology to integrate renewable energy sources in the network [2] and, when compared with conventional distribution systems, new partial systems can operate either while connected to the main power grid or isolated mode operation [3], [4]. A droop control scheme is generally used by paralleling multiple inverters [5]-[7] in which the voltage and frequency of each inverter are adjusted in order to control the active and reactive power.

In an MG in island operation mode, power must be properly shared to loads by the multiple DG units that conform the network. Conventionally, the frequency and voltage magnitude droop control is adopted with the objective to share active and reactive power in an MG, and performed in a decentralized manner without using any communication between DG units [1], [3], [8], [9]. In this control category, the 
active and reactive power are calculated using low-pass filters [10]; consequently, the main focus of droop control is the exchange of average active and reactive power.

Active power sharing is accurate, whereas reactive power sharing depends on line impedances [11], [12]. To improve MG performance, some modified droop control methods have been presented in literature. In [13], an interesting method of dropping $\mathrm{Q}-\mathrm{V}$ points is proposed, where the authors show a new cooperative harmonic filtering strategy for the interface converters of distributed generation sources. A droop control method based on the reactive volt-ampere consumption of harmonics of each interface converter is designed and implemented. However, the shared reactive power errors can hardly be completely eliminated using this method, especially in weak MGs.

Furthermore, the island operation can be considered as one of the most attractive features of an MG, as it guarantees service continuity in the case of network interruption [14]. When the MG is in island operation mode, the DG units must be able to cooperatively regulate the voltage and frequency, and maintain the balance between power generation and the power consumed by the load within the MG. Consequently, the concepts of droop control have been widely adopted in [9], [15], [16] to provide decentralized control of power sharing without relying on communications.

As the MG allows DG units to work in an island operation mode, the system can improve reliability and power quality for customers [14]. However, when operating in island mode, some challenging issues appears such as the difficulty of maintaining the power balance between generation and loads and reactive power sharing [15], [17]. When an MG operates in island mode, the droop control technique provides a decentralized control capability that does not depend on external communication links in the control strategy; although the frequency droop technique can manage active power sharing accurately, the voltage droop technique generally results in a poor reactive power sharing due to the mismatch in the impedances of the DG unit feeders and, also, due to the different values of DG units [18]. Consequently, the reactive power sharing problem in an MG working in island operation mode has received considerable attention in the literature and many control techniques have been developed to address this problem [19]-[23].

Commonly, in high voltage networks, reactive power sharing among generators is not usually a major concern due to capacitive compensation between loads and transmission lines. However, in lowvoltage MGs, the low capacity to supply reactive power from generation sources and compensators, and small distances between units, does not allow an exact distribution of reactive power to avoid overloads [24]. Line impedances and DG impedances significantly affect the reactive power sharing during the operating mode connected to the network and during the island mode due to voltage drops [21]. At present, the voltage controllers in the MGs are unable to share the demand for reactive power among even identical inverters operating in parallel [25]. Some researchers have previously worked on this issue as in [22], which proposes an alternative controller for reactive power sharing between parallel inverters with nominal voltages. Design of control strategies for Distributed generation systems is very important to achieve smoother transition between the grid connected and islanding modes of operation [26]-[28]. Also power management strategy of parallel inveters based system, to enhance the power generation capacity of the existing system with distributed energy sources [29].

The references consulted in this research show that previous works have focused more on performing an active power control while reactive power sharing still requires better applications to improve accuracy. Therefore, the objective of this work is to show that the reactive power can be shared between generators in an MG more accurately by using virtual current injected to the current controller of the inverter in order to optimize the output signal. The main contribution in this paper is related to the virtual currents calculated from each inverter based on the active output power of the inverter. This new current control achieves an accurate exchange of reactive power between generators of the MG when load variations are presented. Section 2 explains the new control strategy for sharing reactive power after each load variation and presents the mathematical formulation of the control method, small-signal model, current loop controller, three-phase half-bridge circuit, output LC filter, line impedance, and the inverter used in the control strategy. In addition, Section 3 shows the results of the simulations performed in a distribution system test case using MATLAB/Simulink software. Finally, Section 4 presents the conclusions and future work.

\section{MATERIALS AND METHOD}

\subsection{Control method}

A strategy using virtual current is proposed as a method to control the reactive power and voltage in the MG when the load changes in certain periods of time. Figure 1 shows a detailed configuration of a DG unit using the proposed control strategy. The P- $\omega$ controller is adopted to regulate the frequency and achieve an accurate exchange of active power between the different distributed generators that conform the MG. 
The design of the controller starts by measuring the current in the capacitor $i_{c}$ and the output voltage $V$. Besides, the active power $P_{d q}$ and reactive power $Q_{d q}$ are calculated by using the output voltage $V$ and the current measured in the output of the system $i_{o}$, both transformed into $d q$ coordinates. Then, the reference voltage $V_{\text {ref }}$ is calculated using the droop control and used to calculate the voltage error. Finally, in the inner loop the voltage error is amplified by the proportional resonant (PR) and used to subtract both the virtual current obtained as the square root of the activate power divided by a virtual impedance, and the current measured in the capacitor and transformed into $d q$ coordinates. The final signal obtained in the inner loop is multiply by a gain P, which increases the signal that is sent to the PWM to make the switch in the inverter obtain the desired current and voltage values.

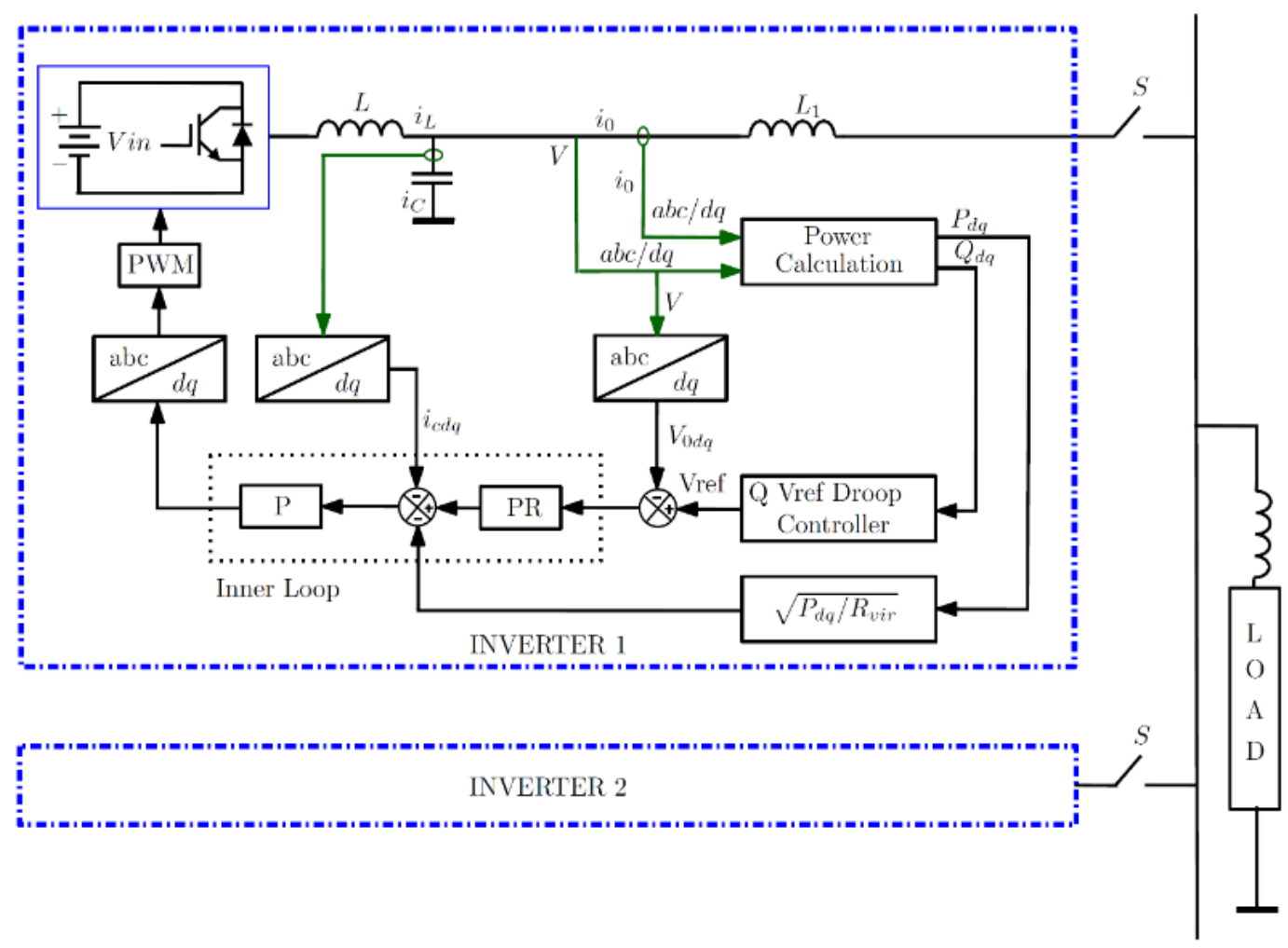

Figure 1. Droop controller with the virtual current

\subsection{Small-signal model}

To analyze the stability of the controller, a small-signal model of the inverters with the proposed control strategy is included. Each inverter is modeled with individual reference and includes the dynamics of the voltage and current controller, LC filter, and line impedance to reach equilibrium. The internal voltage controller is based on a PR structure in the steady-state reference, where generalized integrators are used to achieve a zero steady-state error. Based on the $a b c / d q$-coordinated transformation principle, a three-phase system can be modeled in two independent single-phase systems. Thus, the block diagram of Figure 2 shows the voltage controller in a synchronous reference frame that includes all feedback terms and the four states $A_{d q}$ and $B_{d q}$.

The corresponding state equations can be expressed as in (1) and (2):

$$
\begin{aligned}
& \frac{d A_{d}}{d t}=\left(V_{d}^{* *}-V_{d}\right)-w_{0}{ }^{2} B_{q}+w_{0} A_{q}, \\
& \frac{d A_{q}}{d t}=\left(V_{q}^{* *}-V_{q}\right)-w_{0}{ }^{2} B_{q}-w_{0} A_{d} .
\end{aligned}
$$

Thus, the algebraic equations are expressed as in (3) and (4):

$$
i_{i d}^{*}=k_{p v}\left(V_{d}^{*}-V_{d}\right)+k_{i v} B_{d}+I_{R d},
$$


$i_{i q}{ }^{*}=k_{p v}\left(V_{q}^{*}-V_{q}^{*}\right)+k_{i v} B_{q}+I_{R q}$.

The linearized small-signal state space models of the voltage controller are presented in (5):

$$
\left[\begin{array}{c}
\Delta \dot{\mathrm{A}_{d q}} \\
\Delta B_{d q}
\end{array}\right]=A_{v o l}\left[\begin{array}{l}
\Delta A_{d q} \\
\Delta B_{d q}
\end{array}\right]+B_{v o l 1}\left[\Delta V_{o d q}^{*}\right]+B_{v o l 2}\left[\begin{array}{c}
\Delta i_{i d q} \\
\Delta V_{o d q}
\end{array}\right]
$$
(7), and (8):

Where the terms $A_{v o l}$ is the system matrix. $B_{\text {vol1 }}$ and $B_{\text {vol2 }}$ are the input matrices as shown in (6),

$$
\begin{aligned}
& {\left[\begin{array}{cccc}
0 & w_{0} & -w_{0}{ }^{2} & 0 \\
-w_{0} & 0 & 0 & -w_{0}{ }^{2} \\
1 & 0 & 0 & w_{0} \\
0 & 1 & -w_{0} & 0
\end{array}\right],} \\
& B_{\text {vol } 1}=\left[\begin{array}{ll}
1 & 0 \\
0 & 1 \\
0 & 0 \\
0 & 0
\end{array}\right], \\
& B_{\text {vol } 2}=\left[\begin{array}{cccc}
0 & 0 & 0 & 0 \\
0 & 0 & 0 & 0 \\
-1 & 0 & 0 & 0 \\
0 & -1 & 0 & 0
\end{array}\right] .
\end{aligned}
$$

The linearized small-signal state space models of the voltage controller are presented in (9):

$\left[\Delta i_{d q}^{*}\right]=C_{v o l}\left[\begin{array}{l}\Delta A_{d q} \\ \Delta B_{d q}\end{array}\right]+D_{v o l 1}\left[\Delta V_{o d}^{*}\right]+D_{v o l 2}\left[\begin{array}{c}\Delta i_{i d q} \\ \Delta V_{o d q}\end{array}\right]+D_{v o l 3}\left[\Delta I_{R d q}\right]$,

Where the term $C_{v o l}$ is the output matrix and the terms $D_{v o l 1}, D_{v o l 2}$, and $D_{v o l 3}$ are the feed-forward matrices as shown in (10)-(13):

$$
\begin{aligned}
C_{\text {vol }} & =\left[\begin{array}{cccc}
0 & 0 & k_{i v} & 0 \\
0 & 0 & 0 & K_{i v}
\end{array}\right], \\
D_{\text {vol } 1} & =\left[\begin{array}{cc}
k_{p v} & 0 \\
0 & k_{p v}
\end{array}\right], \\
D_{\text {vol } 2} & =\left[\begin{array}{cccc}
0 & 0 & -k_{p v} & 0 \\
0 & 0 & 0 & -k_{p v}
\end{array}\right], \\
D_{\text {vol3 }} & =\left[\begin{array}{ll}
1 & 0 \\
0 & 1
\end{array}\right] .
\end{aligned}
$$

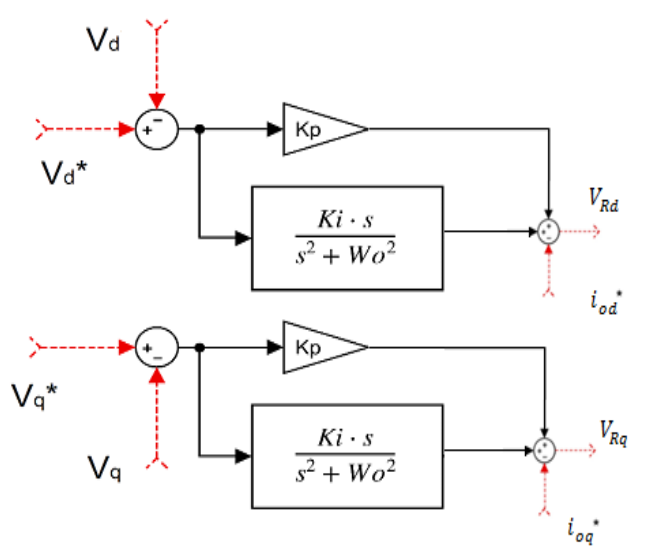

Figure 2. Droop controller with the virtual current 


\subsection{Current loop controller}

The internal current controller is based on a stationary frame structure as shown in Figure 3.

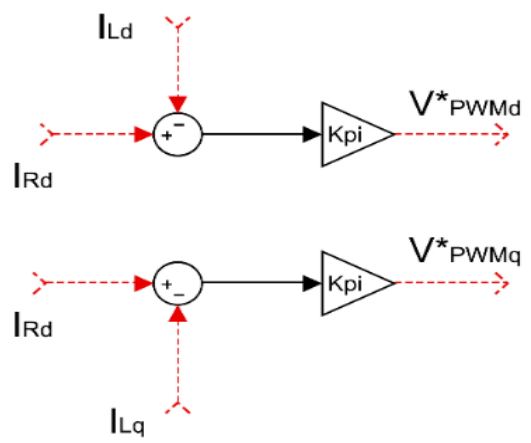

Figure 3. Internal current controller

The input currents on the $d$ and $q$ axes for the controller are $I_{R d}$ and $I_{R q}$, which are the result of the algebraic sum of the output current of the voltage controller $i_{o d}{ }^{*}$ and $i_{o q}{ }^{*}$, minus the virtual current as expressed in (14) and (15):

$$
\begin{aligned}
& I_{R d}=i_{o d}{ }^{*}-i_{o d}{ }^{* *}, \\
& I_{R q}=i_{o q}{ }^{*}-i_{o q}{ }^{* *} .
\end{aligned}
$$

Next, the previous equations related to the $d$ and $q$ axes are obtained by replacing the value of the virtual current $i_{o d}{ }^{* *}$ and $i_{o q}{ }^{* *}$

With its equivalent:

$$
\left(\frac{P_{o d q}}{R_{\text {vir }}}\right)^{\frac{1}{2}}
$$

The algebraic equations for the reference current can be expressed as (16) and (17):

$$
\begin{gathered}
I_{R d}=i_{o d}{ }^{*}-\left(\frac{P_{o d}}{R_{v i r}}\right)^{\frac{1}{2}}, \\
I_{R q}=i_{o q}{ }^{*}-\left(\frac{P_{o q}}{R_{v i r}}\right)^{\frac{1}{2}} .
\end{gathered}
$$

The linearized small-signal state space models of the above equations can be represented in a simple way as shown in (18):

$$
\left[I_{R d q}\right]=C\left[\Delta i_{o d q}^{*}\right]-D\left[\Delta P_{o d q}\right]^{\frac{1}{2}}
$$

where the terms $C$ and $D$ are matrices that can be represented as (19) and (20):

$$
\begin{aligned}
C & =\left[\begin{array}{ll}
1 & 0 \\
0 & 1
\end{array}\right], \\
D & =\left[\begin{array}{cc}
\left(\frac{1}{R_{\text {vir }}}\right)^{\frac{1}{2}} & 0 \\
0 & \left(\frac{1}{R_{\text {vir }}}\right)^{\frac{1}{2}}
\end{array}\right] .
\end{aligned}
$$


From Figure 3, we can observe and obtain the algebraic equation of the internal loop current control, which can be expressed as (21) and (22):

$$
\begin{aligned}
& V_{p w m d}{ }^{*}=k_{p i}\left(I_{R d}-i_{l d}\right), \\
& V_{p w m q}{ }^{*}=k_{p i}\left(I_{R q}-i_{l q}\right) .
\end{aligned}
$$

The linearized small-signal state space models of the current controller loop are presented in (23)(25):

$$
\left[\Delta V_{p w m d q}^{*}\right]=D_{\text {cor } 1}\left[\Delta I_{R d q}\right]+D_{\text {cor } 2}\left[\begin{array}{c}
\Delta i_{i d q} \\
\Delta V_{o d q}
\end{array}\right]
$$

where the terms $D_{\text {cor } 1}$ and $D_{\text {cor } 2}$ are matrices that contain the control parameters $k_{p i}$ as shown in (24) and (25):

$$
\begin{aligned}
D_{\text {cor } 1} & =\left[\begin{array}{cc}
k_{p i} & 0 \\
0 & k_{p i}
\end{array}\right], \\
D_{\text {cor } 2} & =\left[\begin{array}{cccc}
-k_{p i} & 0 & 0 & 0 \\
0 & -k_{p i} & 0 & 0
\end{array}\right] .
\end{aligned}
$$

Based on (11)-(14), the output of the current controller $\Delta V_{p w m d q}{ }^{*}$ can be derivated as in (26):

$$
\begin{aligned}
& {\left[\Delta V_{p w m d q}{ }^{*}\right]=D_{\text {cor } 1} C_{\text {vol }}\left[\begin{array}{c}
\Delta A_{d q} \\
\Delta B_{d q}
\end{array}\right]+D_{\text {cor } 1} D_{\text {vol } 1}\left[\Delta V_{o d}{ }^{*}\right]+\left(D_{\text {cor } 1} D_{\text {vol } 2}+D_{\text {cor } 2}\right)\left[\begin{array}{c}
\Delta i_{i d q} \\
\Delta V_{o d q}
\end{array}\right]+} \\
& \left(D_{\text {cor } 1} D_{v o l 3}\right)\left[\Delta I_{R d q}\right] .
\end{aligned}
$$

\subsection{Three-phase half-bridge circuit and output LC filter}

The corresponding state equations are expressed as shown in (27)-(29):

$$
\begin{aligned}
& \frac{d i_{i d}}{d t}=\frac{-r}{L} i_{i d}+w_{0} i_{l q}+\frac{k_{p w m}}{L} V_{p w m d}{ }^{*}-\frac{1}{L} V_{o d}, \\
& \frac{d i_{i q}}{d t}=\frac{-r}{L} i_{i q}+w_{0} i_{l d}+\frac{k_{p w m}}{L} V_{p w m q}{ }^{*}-\frac{1}{L} V_{o q}, \\
& \frac{d V_{o d}}{d t}=w_{0} V_{o q}+\frac{1}{c} i_{L d}-\frac{1}{c} i_{o d}, \\
& \frac{d V_{o q}}{d t}=-w_{0} V_{o d}+\frac{1}{c} i_{L q}-\frac{1}{c} i_{o q} .
\end{aligned}
$$

The output variables of the LC filter are the state variables $V_{\text {odq }}$. Thus, the (31) represents the linearized small-signal state space:

$$
\left[\begin{array}{c}
\Delta i_{l d q} \\
\Delta V_{o d q}
\end{array}\right]=A_{L C}\left[\begin{array}{c}
\Delta i_{i d q} \\
\Delta V_{o d q}
\end{array}\right]+B_{L C 1}\left[\Delta V_{p w m d q}{ }^{*}\right]+B_{L C 2}\left[\Delta i_{o d q}\right]
$$

where the terms $A_{L C}, B_{L C 1}$, and $B_{L C 2}$ are matrices that consider the parameters of the system as presented in (32)-(34):

$$
A_{L C}=\left[\begin{array}{cccc}
\frac{-r}{L} & w_{0} & \frac{-1}{L} & 0 \\
-w_{0} & \frac{-r}{L} & 0 & \frac{-1}{L} \\
\frac{1}{c} & 0 & 0 & w_{0} \\
0 & \frac{1}{c} & -w_{0} & 0
\end{array}\right],
$$




$$
\begin{aligned}
& B_{L C 1}=\left[\begin{array}{cc}
\frac{k_{p w m}}{L} & 0 \\
0 & \frac{k_{p w m}}{L} \\
0 & 0 \\
0 & 0
\end{array}\right], \\
& B_{L C 2}=\left[\begin{array}{cc}
0 & 0 \\
0 & 0 \\
\frac{-1}{c} & 0 \\
0 & \frac{-1}{c}
\end{array}\right] .
\end{aligned}
$$

In (19), the output of the controller in the current loop $\Delta V_{p w m d q}{ }^{*}$ can be replaced by (26); then, (31) can be expressed as in (35):

$$
\begin{aligned}
& {\left[\begin{array}{c}
\Delta i_{l d q}^{*} \\
\Delta V_{o d q}
\end{array}\right]=A_{L C}\left[\begin{array}{c}
\Delta i_{i d q} \\
\Delta V_{o d q}
\end{array}\right]+B_{L C 1} D_{c o r 1} C_{v o l}\left[\begin{array}{l}
\Delta A_{d q} \\
\Delta B_{d q}
\end{array}\right]+B_{L C 1} D_{c o r 1} D_{v o l 1}\left[\Delta V_{o d q}{ }^{*}\right]+B_{L C 1}\left(D_{c o r 1} D_{v o l 2}+\right.} \\
& \left.D_{c o r 2}\right)\left[\begin{array}{c}
\Delta i_{i d q} \\
\Delta V_{o d q}
\end{array}\right]+B_{L C 1} D_{c o r 1} D_{v o l 3}\left[\Delta i_{R d q}\right]+B_{L C 2}\left[\Delta i_{o d q}\right] .
\end{aligned}
$$

\subsection{Line impedance}

Line impedances are considered in the MG to connect each inverter and the load; thus, real line impedance must be considered in the model to identify the power losses of the circuit. The corresponding state equations can be expressed as in (36) and (37):

$$
\begin{aligned}
& \frac{d_{i o d}}{d t}=\frac{-r_{L}}{L_{i}} i_{\text {od }}+w_{0} i_{o q}+\frac{1}{L_{i}} V_{o d}-\frac{1}{L_{i}} V_{\text {bus } d}, \\
& \frac{d_{i o q}}{d t}=\frac{-r_{L}}{L_{i}} i_{o q}+w_{0} i_{o d}+\frac{1}{L_{i}} V_{o q}-\frac{1}{L_{i}} V_{\text {bus } q} .
\end{aligned}
$$

The output variables of the line impedance are the state variables $i_{\text {odq }}$. Linearized models of smallsignal state space are as in (38):

$$
\left[\Delta i_{\text {ldq }}\right]=A_{L}\left[\Delta i_{o d q}\right]+B_{L 1}\left[\begin{array}{c}
\Delta i_{i d q} \\
\Delta V_{o d q}
\end{array}\right]+B_{L 2}\left[\Delta V_{b u s d q}\right]
$$

where the terms $A_{L}, B_{L 1}$, and $B_{L 2}$ are matrices that consider the parameters of the system as presented in (39)(41):

$$
\begin{aligned}
& A_{L}=\left[\begin{array}{cc}
\frac{-r_{L}}{L_{i}} & w_{0} \\
-w_{0} & \frac{-r_{L}}{L_{i}}
\end{array}\right], \\
& B_{L 1}=\left[\begin{array}{cc}
\frac{1}{L_{i}} & 0 \\
0 & \frac{1}{L_{i}}
\end{array}\right], \\
& B_{L 2}=\left[\begin{array}{cc}
-\frac{1}{L_{i}} & 0 \\
0 & -\frac{1}{L_{i}}
\end{array}\right] .
\end{aligned}
$$

\subsection{Complete model of the inverter}

A complete small-signal state space model of the inverter, as expressed in (42) and (43), can be obtained by combining the status space models of the voltage controller, current controller, LC output filter, and line impedance given by (5), (18), (35), and (38), respectively:

$$
[\Delta X]=A[\Delta X]+B_{1}\left[\Delta V_{o d q}{ }^{*}\right]+B_{2}\left[\Delta V_{\text {bus } d q}\right],
$$




$$
\Delta X=\left[\Delta A_{d q} \Delta B_{d q} \Delta i_{i d q} \Delta V_{o d q} \Delta i_{o d q} \Delta P_{o d q}{ }^{\frac{1}{2}}\right] .
$$

Next, the complete small-signal state space model of the inverter is obtained with the proposed of applying the control strategy that modifies the current controller by combining the different state space models. Herein, the terms $A, B_{1}$, and $B_{2}$ correspond to the matrices shown in (44)-(46):

$$
\begin{aligned}
& A=\left[\begin{array}{cccc}
A_{\text {vol }} & B_{\text {vol } 2} & 0 & 0 \\
0 & 0 & C & -D \\
B_{L C 1} D_{\text {cor } 1} C_{\text {vol }} & A_{L C}+B_{L C 1}\left(D_{\text {cor } 1} D_{\text {vol } 2}+D_{\text {cor } 2}\right) & B_{L C 2}+B_{L C 1}\left(D_{\text {cor } 1} D_{\text {vol } 3} C\right) & 0 \\
0 & B_{l 1} & A_{l} & 0
\end{array}\right] \text {, } \\
& B_{1}=\left[\begin{array}{c}
B_{\text {vol1 }} \\
0 \\
B_{L C 1} D_{\text {cor } 1} D_{\text {vol } 1} \\
0
\end{array}\right] \\
& B_{2}=\left[\begin{array}{c}
0 \\
0 \\
0 \\
B_{L 2}
\end{array}\right] \text {. }
\end{aligned}
$$

\section{RESULTS}

This section shows the results related to the response of the power inverter applied to each generator when the control strategy presented in Section 2 is considered. This control strategy is related to the virtual current considered as an input for the current control of the inverter. This strategy allows sharing the reactive power with precision and regulating the voltage in the nodes. The simulations were carried out by considering a distribution network test case where the loads are connected and disconnected at different periods of time.

\subsection{System test case}

The MG used for this investigation is shown in Figure 4. This network is formed by two distributed generators designed to supply one load. The load considers five household consumptions that are connected and disconnected over time. The power of the distributed generators must be delivered considering the impedances of the lines in order to supply the power of the changing load. In addition, voltage regulation is achieved by using the inverter with the virtual current that changes based on the connected and disconnected loads.

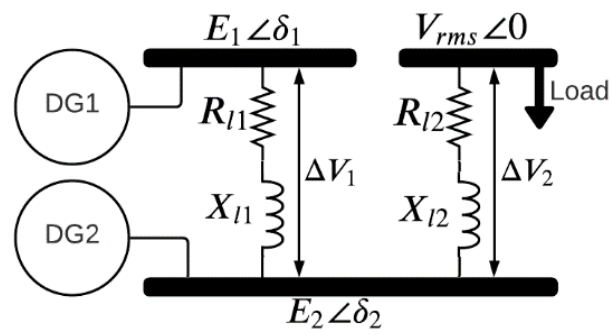

Figure 4. Microgrid test case with two distributed generators and a load.

\subsection{Active power supplied by DG}

Figures 5(a) and 5(b) show the active power delivered by DG1 and DG2, respectively, which consider the droop control versus the virtual current control strategies. The figure shows in red the active power supplied by DGs with the proposed control strategy and in blue the active power supplied by DGs with the droop control strategy. These figures compare the control strategies and behaviors when the loads are connected and disconnected at different times. The active power increases depending on the amount of power load connected to the node. It is observed that the greater the number of loads connected to the node, the greater the active power consumption. 
During the first 12 seconds, a load of $10+\mathrm{j} 0.05 \Omega$ is connected to the load node and both control strategies respond very well to the connection of the load with approximately $1000 \mathrm{~W}$. In the 12 -second period, a load of $15+\mathrm{j} 0.05 \Omega$ is connected for a few seconds and the active power consumption of the load in the node increases by more than $100 \%$ based on the consumption of the previous period. The same load is disconnected from the MG at 24 seconds and, at the same period, a load of $20+\mathrm{j} 0.60 \Omega$ is connected, where the power consumption is reduced. At 36 seconds, a load $25+\mathrm{j} 0.10 \Omega$ is connected, which generates an active power consumption increase of almost $50 \%$ of the initial load. Finally, at 48 seconds, the load $10+\mathrm{j} 0.05 \Omega$ is disconnected and a load $50+\mathrm{j} 0.20 \Omega$ is connected, which causes the active power supplied by the two generators to decrease and allowing the system to deliver less active power.

Figures 5(a) and 5(b) show that the new proposed controller responds faster and better than the droop controller when a load is connected and disconnected. Besides, both controllers share the active power accurately for the changes. However, the proposed control strategy manages to stabilize the active power much faster than the droop control strategy.

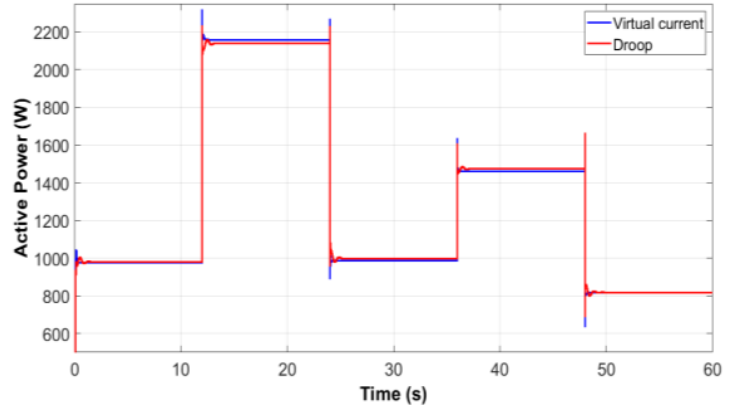

(a)

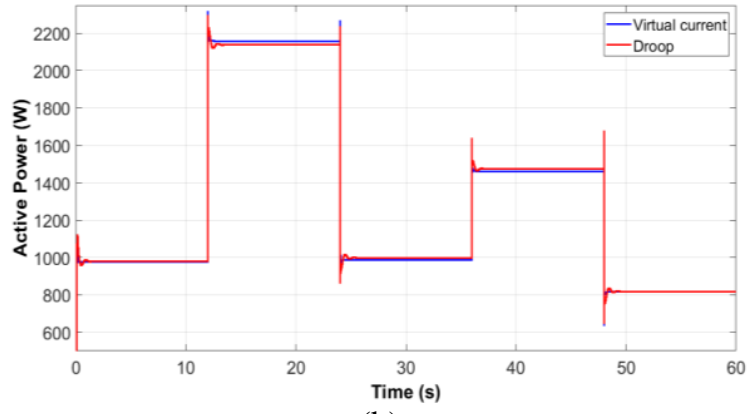

(b)

Figure 5. Active power supplied by (a) DG1 and (b) DG2 when the systems use virtual current (blue line) and droop controls (red line)

\subsection{Reactive power supplied by DG}

Figures 6(a) and 6(b) show the reactive power delivered by DG1 and DG2, respectively, considering the droop control versus the virtual current control strategies. The figure shows in red the reactive power supplied by DGs with the proposed control strategy and in blue the reactive power supplied by DGs with the droop control strategy. These figures compare the control strategies and behaviors when the loads are connected and disconnected at different times. Reactive power increases depending on the amount of power load connected to the node. It is observed that the greater the number of loads connected to the node, the greater the reactive power consumption.

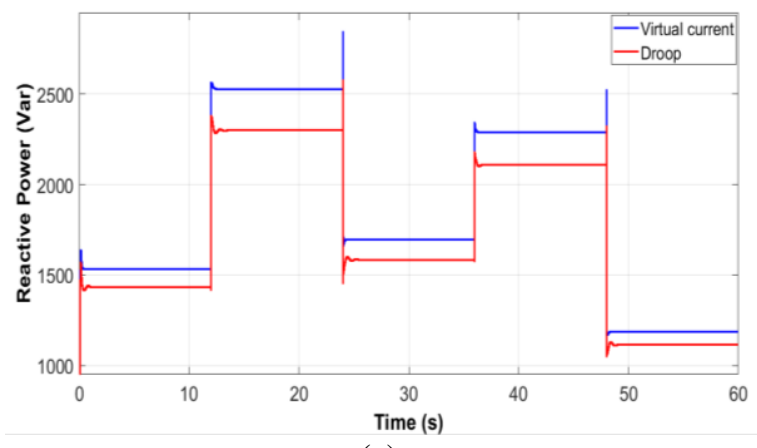

(a)

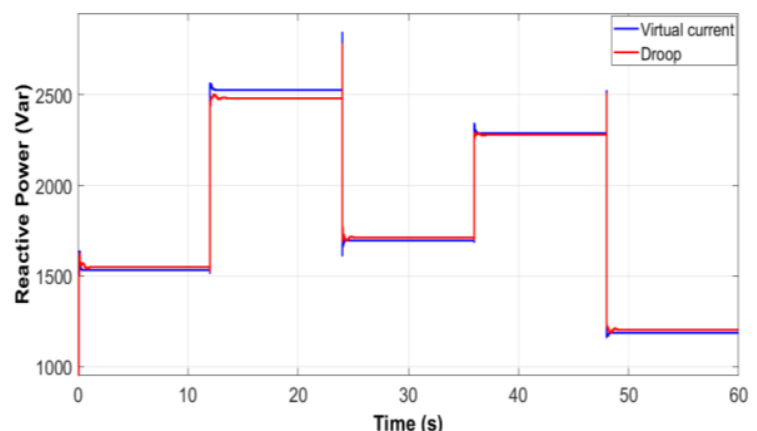

(b)

Figure 6. Reactive power supplied by (a) DG1 and (b) DG2 when the systems uses virtual current (blue line) and droop controls (red line) 
The results show that the proposed virtual current control strategy manages better the reactive power sharing with different load changes than the droop control. During the first 12 seconds, a load of $10+\mathrm{j} 0.05 \Omega$ is connected to identify the response of the control strategy and around 1500 VAR of power consumption is observed. Later, after the 12 -second period, a load of $15+\mathrm{j} 0.05 \Omega$ is connected for a few seconds and the reactive power increases and, based on the consumption of the previous period, this load is disconnected from the MG at 24 seconds. Then, at the same period, a load of $20+\mathrm{j} 0.60 \Omega$ is connected to the node of the $\mathrm{MG}$ and the reactive power is reduced as the load $15+\mathrm{j} 0.05 \Omega$ has been disconnected and the new connected load is not as large as the previous one. Over a period of 36 seconds, a load of $25+\mathrm{j} 0.10 \Omega$ is connected to the network, which generates a reactive power consumption increase, and the control strategy responds quickly to stabilize the power and to share the reactive power with the same amount between the two generators. At 48 seconds, a load of $10+\mathrm{j} 0.05 \Omega$ is disconnected and a load of $50+\mathrm{j} 0.20 \Omega$ is connected, which causes a reactive power decrease in the two generators of approximately $50 \%$ of the previous load.

The results show that the droop control strategy does not allow reactive power to be shared accurately between the generation units as does the new proposed control strategy. The proposed control strategy manages to share with precision the reactive power between two DGs in the MG. Besides, the proposed new controller responds faster and better than the droop controller when a load is connected and disconnected at different times and power.

\subsection{Frequency}

Figure 7 shows the frequency of the system using both the droop and the virtual current controllers when considering different load variations. The figure shows in red the system frequency with the proposed control strategy and, in blue, the system frequency with the droop control strategy. This figure is obtained by considering multiple variations in power loads as described above for the active and reactive power.

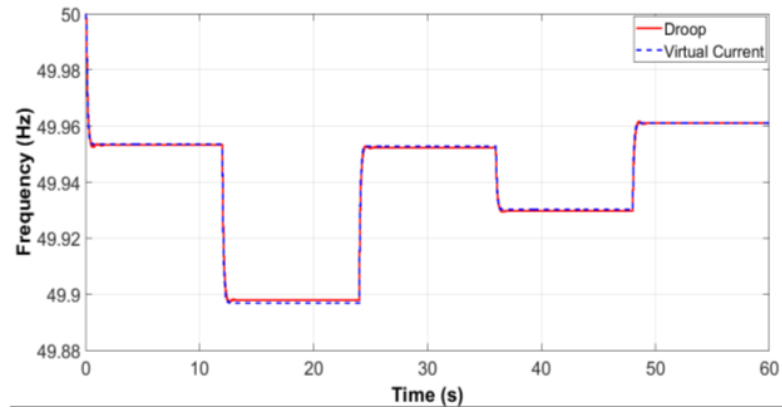

Figure 7. Frequency of the system when using virtual current (blue dotted line) and droop (red line) controls.

Figure 7 shows how both control strategies act when the load changes during different periods of time and the results show that the new proposed controller responds faster and better than the droop controller. Furthermore, the results show that the proposed control strategy ensures that the frequency of the two generators stabilizes at a single value, a few seconds after the load changes. In addition, the more different the change in load on the MG connection, the more abrupt is the change in the frequency value. However, no matter how large the load changes (connection and disconnection of different electrical loads), the controller maintains the frequency close to $50 \mathrm{~Hz}$, which is the desired value.

\subsection{Voltage and currents}

Figure 8 shows the behavior of the RMS voltage at the node where the five electrical loads of the MG are connected. The figure shows in red the voltage in the load with the proposed control strategy and in blue the voltage in the load with the droop control strategy. These results show that at the beginning of the first load connection, the node voltage tends to drop sharply, but immediately the control strategy recovers the voltage close to the original value. Therefore, the proposed control strategy with a virtual current maintains a stable voltage value during the period in which the electrical loads are connected and disconnected. However, when the droop control strategy is used, the voltage drops beyond the proposed method as the proposed new control strategy responds faster and better than the droop controller.

Figure 9 shows the current consumed in the node where the loads are connected. The figure shows in red the current in the load with the proposed control strategy and in blue the current in the load with the droop control strategy. The current is lower with the proposed current control strategy compared to the droop 
control strategy, which brings much benefit because there is less loss in the conductors and winding of the inductive load due to Joule effect.

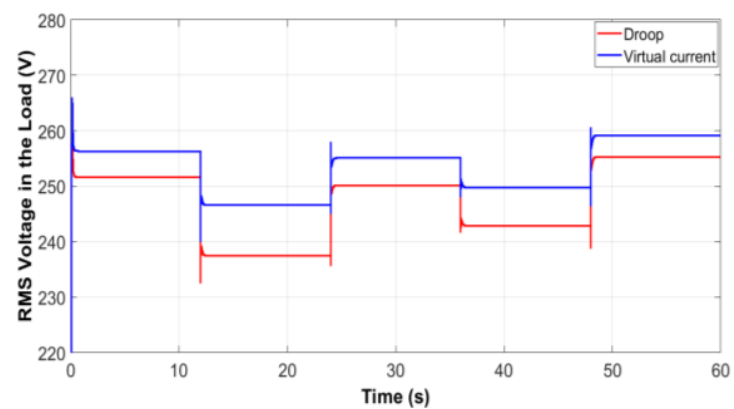

Figure 8. Voltage in the load when using virtual current and droop controls

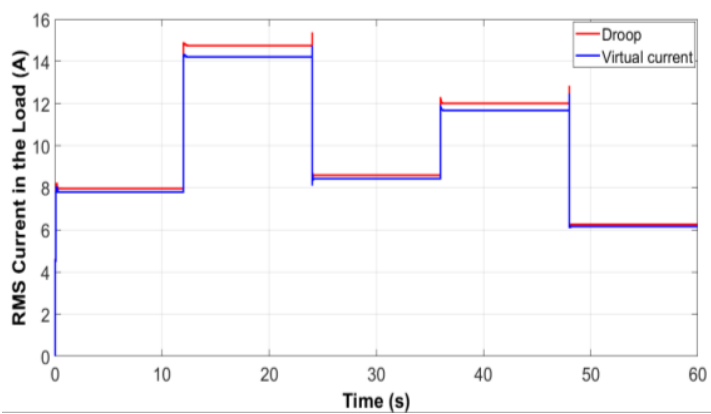

Figure 9. Current in the load when using virtual current and droop controls.

\section{CONCLUSION}

The paper presented a new control strategy that uses a virtual current to share reactive power accurately between two DGs in an MG when electrical loads are connected and disconnected at different time periods. Results were obtained for a system with two distributed generators and a load with five different power consumptions, in which the reactive power shared was correctly distributed between the two generators of the MG, according to the time period that corresponds to the variation of the load. Therefore, within a few moments, the reactive power supplied by the distributed generators increases and, in another time period, it decreases to regulate the voltage in the MG. Therefore, the control strategy based on an adaptive virtual current related to the output power of the inverters works successfully. The proposed control strategy effectively regulates the frequency close to $50 \mathrm{~Hz}$ and also maintains the active and reactive power balance. The strategy can be easily adapted to the MG to share accurately the active and reactive power.

\section{ACKNOWLEDGEMENTS}

The authors thank COLCIENCIAS and the National Doctorate program and the Universidad Nacional de Colombia, Sede Manizales and Sede Medellín.

\section{REFERENCES}

[1] J. M. Guerrero, J. C. Vasquez, J. Matas, L. G. de Vicuna, and M. Castilla, "Hierarchical Control of DroopControlled AC and DC Microgrids-A General Approach Toward Standardization," IEEE Trans. Ind. Electron., vol. 58, no. 1, pp. 158-172, Jan. 2011, doi: 10.1109/TIE.2010.2066534.

[2] R. H. Lasseter, "MicroGrids," in 2002 IEEE Power Engineering Society Winter Meeting. Conference Proceedings (Cat. No.02CH37309), vol. 1, pp. 305-308, doi: 10.1109/PESW.2002.985003.

[3] N. Pogaku, M. Prodanovic, and T. C. Green, "Modeling, Analysis and Testing of Autonomous Operation of an Inverter-Based Microgrid," IEEE Trans. Power Electron., vol. 22, no. 2, pp. 613-625, Mar. 2007, doi: 10.1109/TPEL.2006.890003.

[4] E. Molina, J. E. Candelo-Becerra, and F. E. Hoyos, "Control Strategy to Regulate Voltage and Share Reactive Power Using Variable Virtual Impedance for a Microgrid," Appl. Sci., vol. 9, no. 22, p. 4876, Nov. 2019, doi: 10.3390/app9224876.

[5] A. W. N. Husna, M. A. Roslan, and M. H. Mat, "Droop control technique for equal power sharing in islanded microgrid," International Journal of Power Electronics and Drive Systems (IJPEDS), vol. 10, no. 1, p. 530, 2019 , doi: 10.11591/ijpeds.v10.i1.pp530-537.

[6] S. A. Pizarro, J. E. Candelo-Becerra, and F. E. H. Velasco, "Optimal parameters of inverter-based microgrid to improve transient response," International Journal of Electrical and Computer Engineering (IJECE), vol. 10, no. 1, pp. 637-650, 2020, doi: 10.11591/ijece.v10i1.pp637-650.

[7] O. Feddaoui, R. Toufouti, and L. Djamel, "Active and reactive power sharing in micro grid using droop control," International Journal of Electrical and Computer Engineering (IJECE), vol. 10, no. 3, pp. 2235-2244, 2019, doi: 10.11591/ijece.v10i3.pp2235-2244.

[8] J. M. Guerrero, L. GarciadeVicuna, J. Matas, M. Castilla, and J. Miret, "Output Impedance Design of ParallelConnected UPS Inverters With Wireless Load-Sharing Control," IEEE Trans. Ind. Electron., vol. 52, no. 4, pp. 1126-1135, Aug. 2005, doi: 10.1109/TIE.2005.851634.

[9] D. De and V. Ramanarayanan, "Decentralized Parallel Operation of Inverters Sharing Unbalanced and Nonlinear

Reactive power sharing among distributed generators in a microgrid by using ... (Eder A. Molina-Viloria) 
Loads," IEEE Trans. Power Electron., vol. 25, no. 12, pp. 3015-3025, Dec. 2010, doi: 10.1109/TPEL.2010.2068313.

[10] E. A. A. Coelho, P. C. Cortizo, and P. F. D. Garcia, "Small signal stability for single phase inverter connected to stiff AC system,” pp. 2180-2187, 2003, doi: 10.1109/ias.1999.798756.

[11] J. He and Y. W. Li, "Analysis, design, and implementation of virtual impedance for power electronics interfaced distributed generation," IEEE Trans. Ind. Appl., vol. 47, no. 6, pp. 2525-2538, Nov. 2011, doi: 10.1109/TIA.2011.2168592.

[12] Y. W. Li, "Control and resonance damping of voltage-source and current-source converters with LC filters," IEEE Trans. Ind. Electron., vol. 56, no. 5, pp. 1511-1521, 2009, doi: 10.1109/TIE.2008.2009562

[13] T. L. Lee and P. T. Cheng, "Design of a new cooperative harmonic filtering strategy for distributed generation interface converters in an islanding network," IEEE Trans. Power Electron., vol. 22, no. 5, pp. 1919-1927, Sep. 2007, doi: 10.1109/TPEL.2007.904200.

[14] M. A. Zamani, T. S. Sidhu, and A. Yazdani, "Investigations Into the Control and Protection of an Existing Distribution Network to Operate as a Microgrid: A Case Study," IEEE Trans. Ind. Electron., vol. 61, no. 4, pp. 1904-1915, Apr. 2014, doi: 10.1109/TIE.2013.2267695.

[15] J. Rocabert, A. Luna, F. Blaabjerg, and P. Rodríguez, "Control of Power Converters in AC Microgrids," IEEE Trans. Power Electron., vol. 27, no. 11, pp. 4734-4749, Nov. 2012, doi: 10.1109/TPEL.2012.2199334.

[16] I. U. Nutkani, P. C. Loh, and F. Blaabjerg, "Droop Scheme With Consideration of Operating Costs," IEEE Trans. Power Electron., vol. 29, no. 3, pp. 1047-1052, Mar. 2014, doi: 10.1109/TPEL.2013.2276251.

[17] C. K. Lee, B. Chaudhuri, and S. Y. Hui, "Hardware and Control Implementation of Electric Springs for Stabilizing Future Smart Grid With Intermittent Renewable Energy Sources," IEEE J. Emerg. Sel. Top. Power Electron., vol. 1, no. 1, pp. 18-27, Mar. 2013, doi: 10.1109/JESTPE.2013.2264091.

[18] J. Kim, J. M. Guerrero, P. Rodriguez, R. Teodorescu, and K. Nam, "Mode Adaptive Droop Control With Virtual Output Impedances for an Inverter-Based Flexible AC Microgrid," IEEE Trans. Power Electron., vol. 26, no. 3, pp. 689-701, Mar. 2011, doi: 10.1109/TPEL.2010.2091685.

[19] J. M. Guerrero, J. Matas, L. Garcia de Vicuna, M. Castilla, and J. Miret, "Decentralized Control for Parallel Operation of Distributed Generation Inverters Using Resistive Output Impedance," IEEE Trans. Ind. Electron., vol. 54, no. 2, pp. 994-1004, Apr. 2007, doi: 10.1109/TIE.2007.892621.

[20] A. Tuladhar, Hua Jin, T. Unger, and K. Mauch, "Control of parallel inverters in distributed AC power systems with consideration of line impedance effect," IEEE Trans. Ind. Appl., vol. 36, no. 1, pp. 131-138, 2000, doi: $10.1109 / 28.821807$

[21] Yun Wei Li and Ching-Nan Kao, "An Accurate Power Control Strategy for Power-Electronics-Interfaced Distributed Generation Units Operating in a Low-Voltage Multibus Microgrid," IEEE Trans. Power Electron., vol. 24, no. 12, pp. 2977-2988, Dec. 2009, doi: 10.1109/TPEL.2009.2022828.

[22] Q.-C. Zhong, "Robust Droop Controller for Accurate Proportional Load Sharing Among Inverters Operated in Parallel," IEEE Trans. Ind. Electron., vol. 60, no. 4, pp. 1281-1290, Apr. 2013, doi: 10.1109/TIE.2011.2146221.

[23] C.-T. Lee, C.-C. Chu, and P.-T. Cheng, "A New Droop Control Method for the Autonomous Operation of Distributed Energy Resource Interface Converters," IEEE Trans. Power Electron., vol. 28, no. 4, pp. 1980-1993, Apr. 2013, doi: 10.1109/TPEL.2012.2205944.

[24] J. W. Simpson-Porco, Q. Shafiee, F. Dorfler, J. C. Vasquez, J. M. Guerrero, and F. Bullo, "Secondary Frequency and Voltage Control of Islanded Microgrids via Distributed Averaging," IEEE Trans. Ind. Electron., vol. 62, no. 11, pp. 7025-7038, Nov. 2015, doi: 10.1109/TIE.2015.2436879.

[25] J. A. P. Lopes, C. L. Moreira, and A. G. Madureira, "Defining Control Strategies for MicroGrids Islanded Operation," IEEE Trans. Power Syst., vol. 21, no. 2, pp. 916-924, May 2006, doi: 10.1109/TPWRS.2006.873018.

[26] V. Lavanya and N. S. Kumar, "Control strategies for seamless transfer between the grid-connected and islanded modes of a microgrid system," International Journal of Electrical and Computer Engineering (IJECE), vol. 10, no. 5, pp. 4490-4506, 2020, doi: 10.11591/ijece.v10i5.pp4490-4506.

[27] A. Chaithanakulwat, "Development of DC voltage control from wind turbines using proportions and integrals for Three-phase grid-connected inverters," International Journal of Electrical and Computer Engineering (IJECE), vol. 10, no. 2, pp. 1701-1711, 2020, doi: 10.11591/ijece.v10i2.pp1701-1711

[28] Suroso, D. T. Nugroho, Amran, and T. Noguchi, "Parallel operation of current-source inverter for low-voltage high-current grid-connected photovoltaic system," International Journal of Electrical and Computer Engineering (IJECE), vol. 9, no. 4, pp. 2220-2229, 2019, doi: 10.11591/ijece.v9i4.pp2220-2229.

[29] N. Chaitanya, P. Sujatha, and K. C. Sekhar, "Current Controller Based Power Management Strategy for Interfacing DG Units to Micro Grid," International Journal of Electrical and Computer Engineering (IJECE), vol. 7, no. 5, p. 2300, 2017, doi: 10.11591/ijece.v7i5.pp2300-2308. 


\section{BIOGRAPHIES OF AUTHORS}
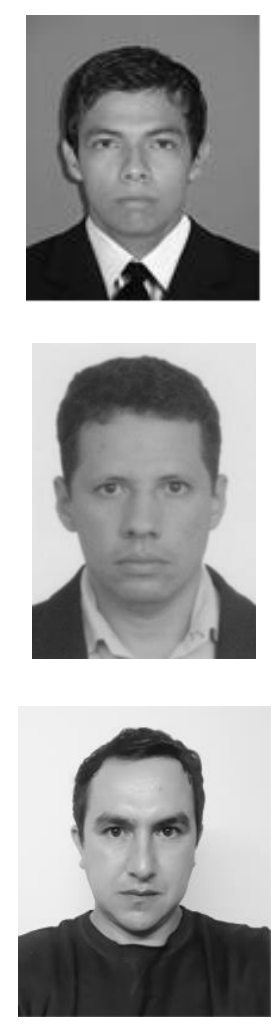

Eder A. Molina Viloria: from Barranquilla, Atlantico, Colombia, received the Bachelor's degree in electrical engineering from Universidad del Norte, Barranquilla - Colombia, in 2008 and his Ph.D. in Engineering with an emphasis in Automatic Engineering in 2020 from Universidad Nacional de Colombia. His employment experiences include the Reficar-Ecopetrol, SENA, ITSA, and Universidad del Norte. His research interests include microgrid, distributed generation, operation, and control of power systems; artificial intelligence; and smart grids. He is a member of the Research Group - GIISTA, at the Tecnológico de Antioquia, Institución Universitaria. https://orcid.org/0000-0002-1052-7207.

John E. Candelo-Becerra: received his Bs. degree in Electrical Engineering in 2002 and his Ph.D. in Engineering with an emphasis in Electrical Engineering in 2009 from Universidad del Valle, Cali - Colombia. His employment experiences include the Empresa de Energía del Pacífico EPSA, Universidad del Norte, and Universidad Nacional de Colombia - Sede Medellín. $\mathrm{He}$ is now an Assistant Professor of the Universidad Nacional de Colombia - Sede Medellín, Colombia. His research interests include: engineering education; planning, operation, and control of power systems; artificial intelligence; and smart grids. He is a Senior Researcher in Colciencias and a member of the Applied Technologies Research Group - GITA, at the Universidad Nacional de Colombia. https://orcid.org/0000-0002-9784-9494.

Fredy Edimer Hoyos: received his BS and MS degree from the National University of Colombia, at Manizales, Colombia, in Electrical Engineering and Industrial Automation, in 2006 and 2009, respectively, and an Industrial Automation Ph.D. in 2012. Dr. Hoyos is currently an Associate Professor of the Science Faculty, School of Physics, at the National University of Colombia, at Medellin, Colombia. His research interests include nonlinear control, system modeling, nonlinear dynamics analysis, control of nonsmooth systems, and power electronics, with applications extending to a broad area of technological processes. Dr. Hoyos is an Associate Researcher in Colciencias and a member of the Applied Technologies Research Group (GITA) at the Universidad Nacional de Colombia. https://orcid.org/0000-0001-8766-5192). 